\title{
Influence of Lavander Essential Oil Addition on Passion Fruit Oil Nanoemulsions: Stability and In vivo Study
}

Rocha- Filho PA $^{1 *}$, Camargo MFP ${ }^{1}$, Ferrari $\mathbf{M}^{2}$ and Maruno $\mathbf{M}^{1}$

${ }^{1}$ Department of Pharmaceutical Sciences, Faculty of Pharmaceutical Sciences of Ribeirão Preto, University of São Paulo, Avenida do Café, s/n. Bairro Monte Alegre, Ribeirão Preto Brazil

${ }^{2}$ Department of Pharmacy, University of Rio Grande do Norte, Caicó, RN, Brazil

\begin{abstract}
Nanoemulsions present droplets between 20 to $500 \mathrm{~nm}$. It can be obtained by high-energy or low-energy methods. The aim of this study was to evaluate the influence of Lavander Essential Oil (LEO) in the formation of Passion Fruit Oil nanoemulsions, water and a blend of nonionic surfactants. The results show a reduction in droplet size with the addition of LEO, which can be explained by the possibility of essential oil molecules to penetrate into the interface and change their properties.
\end{abstract}

Keywords: Nanoemulsion; Passion fruit oil; Lavander essential oil; Emulsion phase inversion

\section{Introduction}

Emulsions are vehicles of great importance in the cosmetics and pharmaceutical industry, as it allows the encapsulation of active / hydrophilic and lipophilic drugs in the same formulation and allow also the control of sensory formulation characteristics. Nanoemulsions are emulsified systems with a diameter size between 20 and $500 \mathrm{~nm}$ and show promise in cosmetic science, due to the stability, differentiated sensory aspect and high spreadability capacity through the roughness of the skin forming a more homogeneous film after application. The use of vegetable oils has been widely reported as a basic component or active ingredient in cosmetic formulations, based on the concept that they are safe and biocompatible with the skin. The passion fruit oil is a raw material extracted from the seeds of the passion fruit, and nowadays is used extensively in cosmetic products currently on the market. It is valued for its rich composition in linoleic acid, also naturally present in the skin lipid barrier. The use of essential oils in perfumery is old, but its antimicrobial properties and medicinal use has been widespread intensely, requiring however, that the real benefits are assessed for the stability of the products that contain them. The first report on the antiinflammatory and healing properties of lavender oil is dated 1937, when the french chemist Rene Maurice had his hands burned in the lab and accidentally put them in a tank containing essential lavender oil, believing that the tank contained water. To his surprise the pain was relieved and the burn healed without infection [1,2]. According to the literature, besides its low toxicity for the skin, the essential oil of lavender (Lavandula officinalis ) shows anti-inflammatory and regenerating activity for the skin tissue. The essential oil of lavender (Lavandula officinalis) is employed as antimicrobial, anti-inflammatory and healing in cases of burns, insect bites and other skin inflammation. Studies show that the anti-inflammatory effect is directly related to linalool and linalyl acetate, the major compounds [3,4]. However, this effect is more pronounced when the essential oil is employed associated to others oils than when used alone showing a synergy action mechanism on inflammatory skin process [5]. The aim of this research was to develop nanoemulsions based on passion fruit oil added of lavender essential oil. After the characterization and physico chemical stability analysis of the formulations the anti-inflammatory activity will be evaluated.

\section{Material and Methods}

\section{Material}

The surfactants PEG-15 castor oil $(\mathrm{HLB}=8.3)$; PEG-30 castor oil $(\mathrm{HLB}=11.7)$; $\mathrm{PEG}-40$ castor oil $(\mathrm{HLB}=13.0)$; $\mathrm{PEG}-60$ castor oil $(\mathrm{HLB}=15.0)$; Polysorbate $80(\mathrm{HLB}=15.0)$ and sorbitan monooleate $(\mathrm{HLB}=4.3)$ were donated by Oxiteno (Brazil). The oily phase was composed of Passion Fruit Oil (PFO) (Passion edulis seed oil) and Lavender Essential Oil (LEO) (Lavandula officinalis). The former was purchased from Beraca Sabara (Brazil) and the latter from Bioessencia (Brazil). Silicones derivatives furnished by Dow Corning: 245 Fluid (Decamethylcyclopentasiloxane); 5562 Carbinol Fluid (Bis-Hydroxyethoxypropyl Dimethicone), 190 Fluid. All chemicals were used as received, without further purification.

\section{Methods}

\section{Studies on formulation}

Determination of HLB value: The selection of the required HLB value for the PFO was performed from the value 4.3 (lipophilic surfactant/ sorbitan monooleate/Span 80 ) to the value 15.0 (hydrophilic surfactant/ polysorbate 80/Tween 80 ) (Equation 1) [6]. The emulsions were prepared by Emulsion Phase Inversion (EPI) method: the aqueous phase and oily (+ surfactants blend) phase were heated at $75 \pm 3^{\circ} \mathrm{C}$ separately, and the aqueous phase was added on the oily phase (passion fruit oil added or not with lavender essential oil) under $600 \mathrm{rpm}$ (Fisatom, 713-D model, Brazil) and then stirred until cooled to $25 \pm 3^{\circ} \mathrm{C}$. The total percentage of the surfactant blend was $5.0 \%$ and $10.0 \%$ for the passion fruit oil (Table 1) [6]. Emulsions composed only by Passion Fruit Oil (PFO) were studied at concentrations from 5.0 to 15.0, keeping the concentration of the surfactant blend at $5.0 \%$ (Table 2).

*Corresponding author: Rocha- Filho PA, Department of Pharmaceutical Sciences, Faculty of Pharmaceutical Sciences of Ribeirão Preto, University of São Paulo, Avenida do Café, s/n. Bairro Monte Alegre, Ribeirão Preto Brazil, Tel: 55 (16) 3602-4273; Fax: 55 (16) 3602-4881; E-mail: pedranjo@fcfrp.usp.br

Received March 01, 2014; Accepted April 17, 2014; Published April 23, 2014

Citation: Rocha- Filho PA, Camargo MFP, Ferrari M, Maruno M (2014) Influence of Lavander Essential Oil Addition on Passion Fruit Oil Nanoemulsions: Stability and In vivo Study. J Nanomed Nanotechnol 5: 198. doi:10.4172/2157-7439.1000198

Copyright: (c) 2014 Rocha- Filho PA, et al. This is an open-access article distributed under the terms of the Creative Commons Attribution License, which permits unrestricted use, distribution, and reproduction in any medium, provided the original author and source are credited. 


\begin{tabular}{|c|c|}
\hline Components & Quantity $(\% \mathbf{w} / \mathbf{w})$ \\
\hline Passion fruit oil & 10.0 \\
Surfactant system & 5.0 \\
Distilled water & 85.0 \\
\hline
\end{tabular}

Table 1: Composition of the emulsions containing passion fruit oil.

\begin{tabular}{|c|c|c|c|}
\hline \multicolumn{4}{|c|}{ Components $(\mathbf{\%} \mathbf{w} / \mathbf{w})$} \\
\hline PFO & PEG- 30 castor oil & Span $^{\circledR} \mathbf{8 0}$ & Purified water \\
\hline 5.0 & 3.85 & 1.15 & 90.0 \\
\hline 6.0 & 3.85 & 1.15 & 89.0 \\
\hline 7.0 & 3.85 & 1.15 & 88.0 \\
\hline 8.0 & 3.85 & 1.15 & 87.0 \\
\hline 9.0 & 3.85 & 1.15 & 86.0 \\
\hline 10.0 & 3.85 & 1.15 & 85.0 \\
\hline 12.0 & 3.85 & 1.15 & 83.0 \\
\hline 15.0 & 3.85 & 1.15 & 80.0 \\
\hline
\end{tabular}

Table 2: Influence of PFO concentration.

\begin{tabular}{|c|c|c|c|c|c|c|c|}
\hline \multicolumn{7}{|c|}{ Components (\% w/w) } \\
\hline LEO & PFO & $\begin{array}{c}\text { Tween }^{\circledR} \\
\mathbf{8 0}\end{array}$ & $\begin{array}{c}\text { PEG- 30 } \\
\text { castor oil }\end{array}$ & $\begin{array}{c}\text { PEG-40 } \\
\text { castor oil }\end{array}$ & $\begin{array}{c}\text { PEG-60 } \\
\text { castor oil }\end{array}$ & Span ${ }^{\circledR 0}$ & $\begin{array}{c}\text { Purified } \\
\text { water }\end{array}$ \\
\hline 2.0 & 5.0 & 2.66 & - & & & 2.34 & 88.0 \\
\hline 5.0 & 5.0 & 2.66 & - & & & 2.34 & 85.0 \\
\hline 2.0 & 5.0 & & 3.85 & & & 1.15 & 88.0 \\
\hline 5.0 & 5.0 & & 3.85 & & & 1.15 & 85.0 \\
\hline 2.0 & 5.0 & & & 3.78 & & 1.72 & 88.0 \\
\hline 5.0 & 5.0 & & & 3.78 & & 1.72 & 85.0 \\
\hline 2.0 & 5.0 & & & & 2.66 & 2.34 & 88.0 \\
\hline 5.0 & 5.0 & & & & 2.66 & 2.34 & 85.0 \\
\hline
\end{tabular}

Table 3: Different proportions of LEO: PFO and surfactants studied.

\begin{tabular}{|c|c|c|c|c|c|}
\hline \multicolumn{7}{|c|}{ Components (\% w/w) } \\
\hline LEO & PFO & $\begin{array}{c}\text { PEG- 30 } \\
\text { castor oil }\end{array}$ & Span $^{\circledR} \mathbf{8 0}$ & $\begin{array}{c}\text { Surfactant } \\
\text { total }\end{array}$ & $\begin{array}{c}\text { Purified } \\
\text { water }\end{array}$ \\
\hline 1.0 & 5.0 & 2.32 & 0.68 & 3.0 & 91.0 \\
\hline 1.0 & 5.0 & 3.08 & 0.92 & 4.0 & 90.0 \\
\hline 1.0 & 5.0 & 3.85 & 1.15 & 5.0 & 89.0 \\
\hline 1.0 & 5.0 & 4.62 & 1.38 & 6.0 & 88.0 \\
\hline 1.0 & 5.0 & 5.40 & 1.60 & 7.0 & 87.0 \\
\hline 2.0 & 5.0 & 2.32 & 0.68 & 3.0 & 90.0 \\
\hline 2.0 & 5.0 & 3.08 & 0.92 & 4.0 & 89.0 \\
\hline 2.0 & 5.0 & 3.85 & 1.15 & 5.0 & 88.0 \\
\hline 2.0 & 5.0 & 4.62 & 1.38 & 6.0 & 87.0 \\
\hline 2.0 & 5.0 & 5.40 & 1.60 & 7.0 & 86.0 \\
\hline 5.0 & 5.0 & 2.32 & 0.68 & 3.0 & 87.0 \\
\hline 5.0 & 5.0 & 3.08 & 0.92 & 4.0 & 86.0 \\
\hline 5.0 & 5.0 & 3.85 & 1.15 & 5.0 & 85.0 \\
\hline 5.0 & 5.0 & 4.62 & 1.38 & 6.0 & 84.0 \\
\hline 5.0 & 5.0 & 5.40 & 1.60 & 7.0 & 83.0 \\
\hline
\end{tabular}

Table 4: Influence of the total surfactants quantity on LEO:PFO emulsions.

Influence of LEO addition on PFO emulsions: To evaluate the influence of LEO on the system, emulsions were prepared by varying the HLB between 8.0 and 11.7 for the system composed by PEG-30 castor oil and sorbitan monooleate and between 8.0 and 13.0 for the system composed by PEG-40 castor oil and sorbitan monooleate (Equation 1 ). Then, different proportions of LEO: PFO and surfactants were evaluate to obtain the most stable emulsions (Table 3).

\section{Studies of pharmacotechnical formulation parameters}

Influence of the amount of surfactant: LEO: PFO emulsions containing 3.0, 4.0, 5.0, 6.0 and $7.0(\% \mathrm{w} / \mathrm{w})$ of the mixture of surfactants (Table 4) were prepared by EPI method. The samples were examined macroscopically and as the particle size distribution within 24 hours and 30 days after preparation.

Influence of differents LEO: PFO proportions: It was also studied emulsions obtention varying the proportions of LEO: PFO (Table 5).

Influence of stirring speed: The emulsions were prepared by EPI method varying the stirrer speed at a constant time (5 minutes):

Method A: 600 rpm (shaker Fisatom)

Method-B: 8,000 rpm (Ultra Turrax)

Method-C: 9,000 rpm (Ultra Turrax)

The emulsions obtained by different methods were subjected to macroscopic analysis, centrifugation and determination of particle size distribution.

Determination of Cloud Point of the hydrophilic surfactant: The determination of cloud temperature was made by heating the solution (1.0\%) of hydrophilic surfactant in milli-Q water. The temperature was monitored with the aid of a thermometer, being considered blurred, when it was not possible to visualize trough the solution an object placed at $5 \mathrm{~cm}$ of distance. The turbidity of the solution was evaluated macroscopically [7].

Determination of the phase inversion temperature: The phase inversion temperature was determined with a conductivity meter (Model DIGIMED ${ }^{\circ} \mathrm{CD}-20$ ) heating the sample and the temperature was monitored from room temperature $25 \pm 2{ }^{\circ} \mathrm{C}$ and at each increment of 5 degrees to 90 degrees. The aqueous phase of the formulation was replaced by solution $10^{-2} \mathrm{M} \mathrm{NaCl}$ to facilitate observation of phase inversion (electrolytes at this concentration did not cause interference to the method $[8,9]$. The inversion of emulsion $\mathrm{O} / \mathrm{W}$ to $\mathrm{W} / \mathrm{O}$ occur is determined when observes a sudden decrease in electrical conductivity value [10].

\section{Additives addition}

Influence of addition of co-surfactants: The surfactant PEG-15 castor oil, PEG-40 castor oil and PEG-40 hydrogenated castor oil are added as co-surfactants at a concentration of $0.5 \%(\mathrm{w} / \mathrm{w})$ (Table 6$)$ for the evaluation of particle size distribution and stability.

Silicone derivatives addition: Silicones derivatives were added

\begin{tabular}{|c|c|c|c|c|c|c|}
\hline formulation & \multicolumn{7}{|c|}{ Components (\% w/w) } \\
\hline & LEO & PFO & $\begin{array}{c}\text { Oil total } \\
\text { quantity }\end{array}$ & $\begin{array}{c}\text { PEG- 30 } \\
\text { castor oil }\end{array}$ & Span $^{\circledR} 80$ & $\begin{array}{c}\text { Purified } \\
\text { water }\end{array}$ \\
\hline & 1.0 & 5.0 & 6.0 & 3.85 & 1.15 & 89.0 \\
\hline & 1.0 & 7.0 & 8.0 & 3.85 & 1.15 & 87.0 \\
\hline & 1.0 & 8.0 & 9.0 & 3.85 & 1.15 & 86.0 \\
\hline & 1.0 & 9.0 & 10.0 & 3.85 & 1.15 & 85.0 \\
\hline & 1.0 & 11.0 & 12.0 & 3.85 & 1.15 & 83.0 \\
\hline & 1.0 & 14.0 & 15.0 & 3.85 & 1.15 & 80.0 \\
\hline & 2.0 & 5.0 & 7.0 & 3.85 & 1.15 & 89.0 \\
\hline & 2.0 & 8.0 & 10.0 & 3.85 & 1.15 & 85.0 \\
\hline & 2.0 & 10.0 & 12.0 & 3.85 & 1.15 & 83.0 \\
\hline & 2.0 & 13.0 & 15.0 & 3.85 & 1.15 & 80.0 \\
\hline & 5.0 & 5.0 & 10.0 & 3.85 & 1.15 & 85.0 \\
\hline & 5.0 & 7.0 & 12.0 & 3.85 & 1.15 & 83.0 \\
\hline & 5.0 & 10.0 & 15.0 & 3.85 & 1.15 & 80.0 \\
\hline
\end{tabular}

Table 5: Influence of differents LEO:PFO proportions. 


\begin{tabular}{|c|c|c|c|c|c|c|c|}
\hline \multicolumn{7}{|c|}{ Components (\% w/w) } \\
\hline LEO & PFO & $\begin{array}{c}\text { PEG- 30 } \\
\text { castor oil }\end{array}$ & Span ${ }^{\circledR 80}$ & $\begin{array}{c}\text { PEG-15 } \\
\text { castor oil }\end{array}$ & $\begin{array}{c}\text { PEG-40 } \\
\text { castor oil }\end{array}$ & $\begin{array}{c}\text { PEG-40 } \\
\text { hydrogenated } \\
\text { castor oil }\end{array}$ & $\begin{array}{c}\text { Purified } \\
\text { water }\end{array}$ \\
\hline 1.0 & 5.0 & 3.85 & 1.15 & 0.5 & - & - & 88.5 \\
\hline 1.0 & 5.0 & 3.85 & 1.15 & & 0.5 & - & 88.5 \\
\hline 1.0 & 5.0 & 3.85 & 1.15 & & & 0.5 & 88.5 \\
\hline 2.0 & 5.0 & 3.85 & 1.15 & 0.5 & - & - & 87.5 \\
\hline 2.0 & 5.0 & 3.85 & 1.15 & & 0.5 & - & 87.5 \\
\hline 2.0 & 5.0 & 3.85 & 1.15 & & & 0.5 & 87.5 \\
\hline 5.0 & 5.0 & 3.85 & 1.15 & 0.5 & - & - & 84.5 \\
\hline 5.0 & 5.0 & 3.85 & 1.15 & & 0.5 & - & 84.5 \\
\hline 5.0 & 5.0 & 3.85 & 1.15 & & & 0.5 & 84.5 \\
\hline
\end{tabular}

Table 6: Influence of addition of co-surfactants.

\begin{tabular}{|c|c|c|c|c|c|c|c|}
\hline \multicolumn{8}{|c|}{ Components (\% w/w) } \\
\hline LEO & PFO & $\begin{array}{l}\text { PEG- } 30 \\
\text { castor oil }\end{array}$ & Span $^{\circledR} 80$ & $\begin{array}{c}\text { Carbinol } \\
5562\end{array}$ & $\begin{array}{c}245 \\
\text { Fluid }^{\circledR}\end{array}$ & $\begin{array}{c}190 \\
\text { Fluid }^{\circledR}\end{array}$ & $\begin{array}{c}\text { Purified } \\
\text { water }\end{array}$ \\
\hline 1.0 & 5.0 & 3.85 & 1.15 & 0.5 & - & - & 88.5 \\
\hline 1.0 & 5.0 & 3.85 & 1.15 & - & 0.5 & - & 88.5 \\
\hline 1.0 & 5.0 & 3.85 & 1.15 & - & - & 0.5 & 88.5 \\
\hline 2.0 & 5.0 & 3.85 & 1.15 & 0.5 & - & - & 87.5 \\
\hline 2.0 & 5.0 & 3.85 & 1.15 & - & 0.5 & - & 87.5 \\
\hline 2.0 & 5.0 & 3.85 & 1.15 & - & - & 0.5 & 87.5 \\
\hline 5.0 & 5.0 & 3.85 & 1.15 & 0.5 & - & - & 84.5 \\
\hline 5.0 & 5.0 & 3.85 & 1.15 & - & 0.5 & - & 84.5 \\
\hline 5.0 & 5.0 & 3.85 & 1.15 & - & - & 0.5 & 84.5 \\
\hline
\end{tabular}

to PFO:LEO nanoemulsions to study the influence on stability and diameter size of these dispersions. Then, carbinol 5562 245 Fluid $^{\circ}$ and 190 Fluid $^{\circ}$ were added (Table 7).

\section{Stability evaluation tests}

Centrifugation Test: The quantity of $5.0 \mathrm{~g}$ of each sample was submitted to a rotation of $3000 \mathrm{rpm}$ during 30 minutes at $25 \pm 2^{\circ} \mathrm{C}$ (Fanen model 206-R- Excelsa Baby II-440 W). Signs of instability such as creaming and phase separation were observed and correlated to droplet size distribution $[11,12]$.

Thermal stress test: Samples were placed in a closed glass recipient and submitted to a range of temperatures $\left(45 \pm 2^{\circ} \mathrm{C}\right.$ to $\left.80 \pm 2^{\circ} \mathrm{C}\right)$ during 30 minutes for each condition in a thermostatic bath (Nova Técnica Ltda model $281 \mathrm{NT}$ ). The increment in the temperature was done in an interval of $5 \pm 2^{\circ} \mathrm{C}[6,12]$

Granulometric distribution measurement: The droplet size distribution was determined through light scattering analyze, using the Coulter Counter DELSA 440SX. This equipment analyses size distribution based on photon correlation spectroscopic. The samples were diluted in distilled water (1:20) before the application in the device sample chamber, considering that dilution does not affect droplet size in nanoemulsion systems [10]. All measurements were carried out in triplicate.

Evaluation of the constituents of lavender oil by GC/MS [13]: The determination of the constituents of lavender oil isolated and from nanoemulsions was made by gas chromatography and mass spectrometry (GC /MS) (Shimadzu QP2010). The column used was DB-5 MS $(30 \mathrm{~cm} \times 0.25 \times 0.25 \mu \mathrm{m})$. The analytical conditions were: carrier gas: helium; injected volume: $1 \mathrm{~mL}$; dilution factor 1.0; column temperature $60^{\circ} \mathrm{C}$, injection temperature $250^{\circ} \mathrm{C}$; flow control -- linear velocity ( $48.1 \mathrm{~cm} / \mathrm{s}$ ); total flow $57.7 \mathrm{~mL} / \mathrm{min}$; column flow: $1.33 \mathrm{~mL} /$ min.; injection flow: $3 \mathrm{~mL} / \mathrm{min}$.; pressure $81.9 \mathrm{Pka}$; injection rate: 40.0 .

The results were analyzed by the data base Wiley and calculation of índex of Kovat 's (equation 2) [14]:

$$
1 \mathrm{~K}=100-. \mathrm{n}=100 . \Delta \mathrm{n} \cdot \frac{(\operatorname{tri}-\operatorname{trn})}{(\operatorname{trm}-\operatorname{trn})}
$$

where:

$\mathrm{IK}=$ Kovats índex; $\mathrm{n}$ - alkane carbon number of the previous sample; $\Delta \mathrm{n}=$ alkane carbon number of the sample that eluted after the less the carbon number of the alkane which elutes before the sample; tri- retention time of test compound; trn - alkane retention time of the sample; trm- alkane retention time of the posterior eluting sample

\section{In vivo study- evaluation of anti-inflammatory activity of emulsions}

The evaluation of the anti-inflammatory activity of the emulsions is taken by erythema induction method using hairless mice and UVB fluorescent lamp as a light source that causes inflammation. The lamp emits radiation in the range of ultraviolet rays $(290-400 \mathrm{~nm})$ with peak emission in $313 \mathrm{~nm}$ (UVA). The animals will be placed in a closed box at a distance of $20 \mathrm{~cm}$ below the lamp [15]. The Chroma Meter Minolta is equipment employed to evaluate system of colors into three parameters: lightness $\left(L^{*}\right)$, proximity of red or green $\left(a^{*}\right)$, near the yellow or blue $\left(b^{*}\right)$ and situate the colors in these three coordinates [15]. Skin redness according to the methodology proposed by Proksch et al. [16] will be analyzed indicates that inflammatory and anti-inflammatory action (increase and decreased of the parameter $\mathrm{a}^{*}$, respectively). After the formation of erythema, in the dorsal region of hairless mice, it will measure the color of the skin of animals, and later will be the application of the "test product" directly on the affected skin. This system makes subjective numerical values in facilitating identification data and color variation providing reliable results [15]. Then:

Group 1- control;

Group 2: passion fruit oil nanoemulsions;

Group 3- passion fruit oil plus lavander oil (5.0\%) nanoemulsions

Group 4- lavander essential oil, only.

The skin color were evaluated in triplicate through the Minolta Chroma Meter Minolta immediately after application and 2, 5, 10, 24, 48 and 72 hours after application of "test product". The value of $\Delta \mathrm{a}^{\star}$ was calculated using the largest value of $\mathrm{a}^{\star}$ obtained minus the value obtained before the irradiation and the results were analyzed by $t$-test $(\mathrm{P}<0.05)$

\section{Results}

The selection of the required HLB value for the passion fruit oil was performed from the value 4.3 (lipophilic surfactant/sorbitan monooleate/Span 80 ) to the value 15.0 (hydrophilic surfactant/ polysorbate 80 /Tween 80 ) being determined equal to 10.0 , and was the only one that did not show instability phenomenon after 24 hours from preparation showing bluish color. The formulation complete is cited in Table 1 [17].

According to Aulton (1995) [18], the mixture of surfactants with final HLB value near to the required by the oily phase favors the production of stable emulsions. 


\begin{tabular}{|c|c|c|c|c|c|c|c|c|c|c|}
\hline \multirow[t]{2}{*}{ formulation } & \multirow[t]{2}{*}{ Centrifugation cycles } & \multicolumn{9}{|c|}{ Thermic stress $\left( \pm 1^{\circ} \mathrm{C}\right)$} \\
\hline & & 40 & 45 & 50 & 55 & 60 & 65 & 70 & 75 & 80 \\
\hline PEG-30 castor oil+ SPAN ${ }^{\circledR} 80$ & $\mathbf{N}$ & $\mathbf{N}$ & $\mathbf{N}$ & $\mathbf{N}$ & $\mathbf{N}$ & $\mathbf{N}$ & $\mathbf{N}$ & $\mathbf{N}$ & $\mathbf{N}$ & $\mathbf{N}$ \\
\hline PEG-30 castor oil+ SPAN ${ }^{\circledR} 80$ & $\mathbf{N}$ & $\mathbf{N}$ & $\mathbf{N}$ & $\mathbf{N}$ & $\mathbf{N}$ & $\mathbf{N}$ & $\mathbf{N}$ & $\mathbf{N}$ & $\mathbf{N}$ & $\mathbf{N}$ \\
\hline PEG-40 castor oil+ SPAN ${ }^{\circledR} 80$ & os & $\mathbf{N}$ & $\mathbf{N}$ & $\mathbf{N}$ & $\mathbf{N}$ & $\mathbf{N}$ & $\mathbf{N}$ & $\mathbf{N}$ & $\mathbf{N}$ & $\mathbf{N}$ \\
\hline PEG-40 castor oil+ SPAN ${ }^{\circledR} 80$ & os & $\mathbf{N}$ & $\mathbf{N}$ & $\mathbf{N}$ & $\mathbf{N}$ & $\mathbf{N}$ & $\mathbf{N}$ & $\mathbf{N}$ & $\mathbf{N}$ & $\mathbf{N}$ \\
\hline PEG-60 castor oil+ SPAN ${ }^{\circledR} 80$ & OS & LC & LC & LC & LC & LC & LC & LC & LC & LC \\
\hline PEG-60 castor oil+ SPAN ${ }^{\circledR} 80$ & os & $\mathrm{Cr}$ & $\mathrm{Cr}$ & $\mathrm{Cr}$ & $\mathrm{Cr}$ & $\mathrm{Cr}$ & $\mathrm{Cr}$ & $\mathrm{Cr}$ & $\mathrm{Cr}$ & $\mathrm{Cr}$ \\
\hline TWEEN $^{\circledR} 80+$ SPAN $^{\circledR} 80$ & OS & _ & _ & _- & _ & _- & _- & _ & _- & _ \\
\hline TWEEN $^{\circledR} 80+$ SPAN $^{\circledR} 80$ & OS & _ & - & - & - & - & - & - & - & - \\
\hline
\end{tabular}

OS= phase separation; $\mathrm{N}=$ normal (stable); $\mathrm{LC}=$ light cremeation; $\mathrm{Cr}=$ cremeation

Table 8: Stability results for centrifugation and thermic stress evaluation for PFO emulsions.

\begin{tabular}{|c|c|c|c|c|c|c|c|c|c|c|}
\hline PFO (\% w/w) & Centrifugation cycles & \multicolumn{9}{|c|}{ Thermic stress $\left.\mathbf{( \pm 1}{ }^{\circ} \mathbf{C}\right)$} \\
\hline & & 40 & 45 & 50 & 55 & 60 & 65 & 70 & 75 & 80 \\
\hline 5.0 & $\mathbf{N}$ & $\mathbf{N}$ & $\mathbf{N}$ & $\mathbf{N}$ & $\mathbf{N}$ & $\mathbf{N}$ & $\mathbf{N}$ & $\mathbf{N}$ & $\mathbf{N}$ & $\mathbf{N}$ \\
\hline 6.0 & $\mathbf{N}$ & $\mathbf{N}$ & $\mathbf{N}$ & $\mathbf{N}$ & $\mathbf{N}$ & $\mathbf{N}$ & $\mathbf{N}$ & $\mathbf{N}$ & $\mathbf{N}$ & $\mathbf{N}$ \\
\hline 7.0 & $\mathbf{N}$ & $\mathbf{N}$ & $\mathbf{N}$ & $\mathbf{N}$ & $\mathbf{N}$ & $\mathbf{N}$ & $\mathbf{N}$ & $\mathbf{N}$ & $\mathbf{N}$ & $\mathbf{N}$ \\
\hline 8.0 & Cl & $\mathbf{N}$ & $\mathbf{N}$ & $\mathbf{N}$ & $\mathbf{N}$ & $\mathbf{N}$ & IC & IC & IC & OS \\
\hline 9.0 & Cl & $\mathbf{N}$ & $\mathbf{N}$ & $\mathbf{N}$ & $\mathbf{N}$ & $\mathbf{N}$ & LC & IC & IC & OS \\
\hline 10.0 & OS & LC & LC & LC & LC & LC & OS & PS & PS & OS \\
\hline 12.0 & OS & IC & IC & IC & IC & IC & OS & PS & PS & OS \\
\hline 15.0 & OS & IC & IC & IC & IC & IC & OS & PS & PS & OS \\
\hline
\end{tabular}

$\mathrm{N}=$ normal; $\mathrm{PS}=$ phase separation: $\mathrm{LC}=$ light cremeation; $\mathrm{IC}=$ intense cremeation

Table 9: Stability results for centrifugation and thermic stress evaluation emulsions (increase quantity for PFO).

\begin{tabular}{|c|c|c|c|c|c|c|c|c|c|c|}
\hline \multirow[t]{2}{*}{ PFO:LEO (\% w/w) } & \multirow[t]{2}{*}{ Centrifugation cycles } & \multicolumn{9}{|c|}{ Thermic stress $\left( \pm 1^{\circ} \mathrm{C}\right)$} \\
\hline & & 40 & 45 & 50 & 55 & 60 & 65 & 70 & 75 & 80 \\
\hline $5.0: 1.0$ & $N$ & $N$ & $N$ & $N$ & $N$ & $N$ & $N$ & $N$ & $N$ & os \\
\hline $7.0: 1.0$ & $\mathbf{N}$ & $\mathbf{N}$ & $\mathbf{N}$ & $\mathbf{N}$ & $\mathbf{N}$ & $\mathbf{N}$ & $\mathbf{N}$ & $\mathbf{N}$ & $\mathbf{N}$ & os \\
\hline $8.0: 1.0$ & $\mathbf{N}$ & $\mathbf{N}$ & $\mathbf{N}$ & $\mathbf{N}$ & $\mathbf{N}$ & $\mathbf{N}$ & $\mathbf{N}$ & $\mathbf{N}$ & $\mathbf{N}$ & OS \\
\hline $9.0: 1.0$ & LC & $\mathbf{N}$ & $\mathbf{N}$ & $\mathbf{N}$ & $\mathbf{N}$ & $\mathbf{N}$ & $\mathbf{N}$ & $\mathbf{N}$ & $\mathbf{N}$ & OS \\
\hline 11.0: 1.0 & LC & LC & LC & LC & LC & LC & IC & PS & PS & os \\
\hline 14.0:1.0 & LC & LC & LC & LC & LC & LC & IC & PS & PS & OS \\
\hline $5.0: 2.0$ & $N$ & $N$ & $N$ & $N$ & $N$ & $N$ & $N$ & $N$ & $N$ & OS \\
\hline $8.0: 2.0$ & $\mathbf{N}$ & $\mathbf{N}$ & $\mathbf{N}$ & $\mathbf{N}$ & $\mathbf{N}$ & $\mathbf{N}$ & $\mathbf{N}$ & $\mathbf{N}$ & $\mathbf{N}$ & OS \\
\hline $10.0: 2.0$ & LC & $\mathbf{N}$ & $\mathbf{N}$ & $\mathbf{N}$ & $\mathbf{N}$ & $\mathbf{N}$ & $\mathbf{N}$ & $\mathbf{N}$ & IC & OS \\
\hline 13.0:2.0 & IC & $\mathbf{N}$ & $\mathbf{N}$ & $\mathbf{N}$ & $\mathbf{N}$ & $\mathbf{N}$ & IC & IC & PS & OS \\
\hline $5.0: 5.0$ & $N$ & $N$ & $N$ & $N$ & $N$ & $N$ & $N$ & $N$ & PS & OS \\
\hline $7.0: 5.0$ & $\mathbf{N}$ & $\mathbf{N}$ & $\mathbf{N}$ & $\mathbf{N}$ & $\mathbf{N}$ & $\mathbf{N}$ & $\mathbf{N}$ & $\mathbf{N}$ & PS & os \\
\hline 10.0: 5.0 & $\mathbf{N}$ & $\mathbf{N}$ & $\mathbf{N}$ & $\mathbf{N}$ & $\mathbf{N}$ & $\mathbf{N}$ & $\mathbf{N}$ & $\mathbf{N}$ & PS & OS \\
\hline
\end{tabular}

Table 10: Stability results for centrifugation and thermic stress evaluation for passion fruit oil nanoemulsions added with lavander oil.

The HLB value must be determined for each surfactant system studied, whereas the solubility of the surfactant between the aqueous and oily phases can be influenced by the presence of other compounds present in the formulation, as well as the $\mathrm{pH}$ value, presence of ions and organic solvents in the aqueous phase [19].

Emulsions with HLB values 9.0 and 10.0 showed a higher physical stability a bluish reflex.

On the macroscopic analysis, formulations where LEO was added showed characteristics of emulsions with tiny droplets size such as: bluish reflex, translucency, higher intrinsic stability, especially for formulations containing $5.0 \%$ of PFO added with $1.0 \%$ of LEO (PFO:LEO- 5.0:1.0), 2.0\% of LEO (PFO:LEO- 5.0:2.0) and 5.0\% of LEO (PFO:LEO- 5.0:5.0).

\section{Emulsions evaluation tests}

Centrifugation test and thermal stress: As we can see in Table 8 PFO nanoemulsions obtained with the surfactants blend PEG-
30 castor oil/ Span 80 and PEG- 40 castor oil/ Span 80 were stable for centrifugation test and show stability at $80^{\circ} \mathrm{C}$ in thermic stress test. Others surfactants pairs give unstable PFO and /or PFO:LEO nanoemulsions. Emulsions containing higher amount of PFO phase presented signs of instability after centrifugation for emulsions containing PFO only, as well as for emulsions where LEO was added (Table 9). It is probable that the amount of surfactant used was not enough to obtaining a structured interfacial film in emulsions with a high amount of oily phase. In the thermal stress, the nanoemulsions composed by 6.0 to 9.0 of PFO present phase separation only in $80^{\circ} \mathrm{C}$, showing the high stability of the system. Other concentrations of PFO $(10.0,12.0$ and $15.0 \%)$ were destabilized at the beginning of the test. It can be due to the low surfactant quantities in these systems (Table 10).

In the thermal stress, formulations containing PFO:LEO (11.0:1.0 and 14.0:1.0) showed phase separation at $70^{\circ} \mathrm{C}$ (Table 10), which may be due to destabilization of the system by evaporation of its volatile constituents. It is known that the motion of molecules of a 


\begin{tabular}{|c|c|c|c|c|}
\hline $\begin{array}{c}\text { PFO:LEO } \\
(\% \mathbf{w} / \mathbf{w})\end{array}$ & $\begin{array}{c}\text { Electrical conductivity value } \\
(\mathbf{m S / c m})\end{array}$ & \multicolumn{2}{|c|}{ pH values } \\
\hline & $\mathbf{4 8}$ hs & $\begin{array}{c}\text { After thermic } \\
\text { stress }\end{array}$ & $\mathbf{4 8 h s}$ & $\begin{array}{c}\text { After thermic } \\
\text { stress }\end{array}$ \\
\hline $6.0: 0.0$ & $55.0 \pm 0.35$ & $56.0 \pm 0.07$ & $6.6 \pm 0.007$ & $6.50 \pm 0.02$ \\
\hline $7.0: 0.0$ & $55.0 \pm 0.07$ & $54.0 \pm 0.42$ & $6.41 \pm 0.007$ & $6.38 \pm 0.007$ \\
\hline $5.0: 1.0$ & $49.4 \pm 0.0$ & $64.7 \pm 0.30$ & $6.42 \pm 0.007$ & $4.8 \pm 0.020$ \\
\hline $7.0: 1.0$ & $48.4 \pm 0.10$ & $63.7 \pm 0.23$ & $6.48 \pm 0.028$ & $5.15 \pm 0.005$ \\
\hline $8.0: 1.0$ & $50.5 \pm 0.23$ & $65.0 \pm 0.38$ & $6.52 \pm 0.028$ & $5.22 \pm 0.005$ \\
\hline $5.0: 2.0$ & $51.2 \pm 0.58$ & $72.1 \pm 0.51$ & $6.14 \pm 0.007$ & $4.46 \pm 0.011$ \\
\hline $8.0: 2.0$ & $50,1 \pm 0.52$ & $63.8 \pm 0.20$ & $6.53 \pm 0.014$ & $4.71 \pm 0.005$ \\
\hline $5.0: 5.0$ & $54.5 \pm 0.15$ & $78.1 \pm 0.20$ & $5.21 \pm 0.007$ & $4.23 \pm 0.0$ \\
\hline $7.0: 5.0$ & $51.3 \pm 0.32$ & $80.0 \pm 0.0$ & $5.77 \pm 0.014$ & $4.37 \pm 0.005$ \\
\hline $10.0: 5.0$ & $52.7 \pm 0.28$ & $82.0 \pm 0.30$ & $5.77 \pm 0.021$ & $4.36 \pm 0.005$ \\
\hline
\end{tabular}

Table 11: PFO:LEO nanoemulsion conductivity and $\mathrm{pH}$ values.

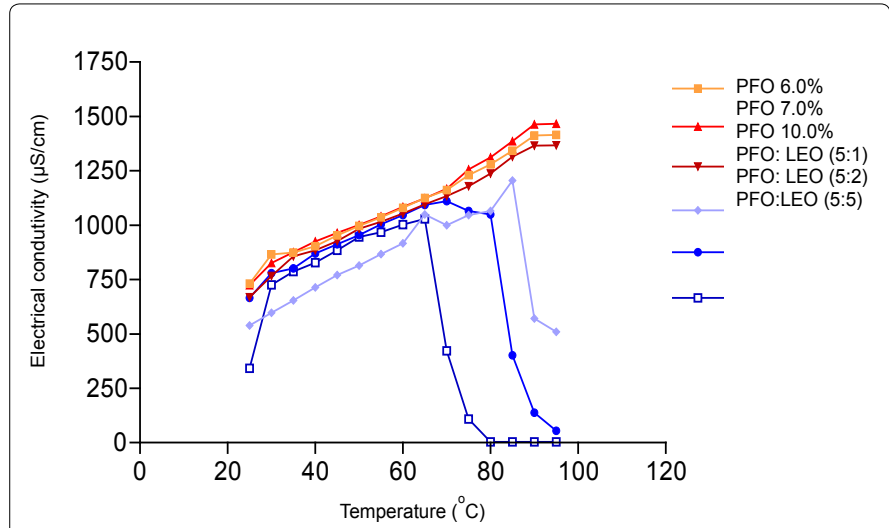

Figure 1: PFO and PFO: LEO nanoemulsions electrical conductivity values as function of temperature $\left({ }^{\circ} \mathrm{C}\right)$.

liquid increase with the increasing of the temperature, what favors the tendency of molecules to escape into the vapor phase, causing a consequent increasing in the vapor pressure [19]. The essential oils have a high vapor pressure, what means that it may volatilize in low temperatures. The phase separation can be due to the reorganization of the system, since essential oils present low vapor pressure and when submitted to heating its molecules might have caused the rupture of the interface followed by coalescence.

The formulations PFO:LEO (5.0:1.0), PFO:LEO (7.0:1.0), PFO:LEO (8.0: 1.0), PFO:LEO (5.0: 2.0), PFO:LEO (8.0:2.0), PFO:LEO (5.0:5.0), PFO:LEO (7.0:5.0), PFO:LEO (10.0:5.0), PFO:LEO (6.0:7.0) were stable after centrifugation and thermal stress tests and were submitted to the studies of granulometric analysis.

\section{Cloud point of the hydrophilic surfactant}

A relevant turbidity for the surfactant PEG-30 castor oil was observed when the solution reached $80 \pm 2^{\circ} \mathrm{C}$. The cloud point is related to the change in the surfactant affinity for the water when temperature increases. With the temperature increment there is a dehydration of the EO molecules of the surfactant chain and at a certain temperature value, the surfactant becomes insoluble in water, causing the solution turbidity [7].

The cloud point determination is a complementary test to the phase inversion temperature determination because it does not consider the influence of other formulation components, which can influence in the affinity hydro-lipophilic [18].
For the nanoemulsions containing only PFO as component of oily phase, the conductivity increased with the increase of temperature (Table 11), which suggests that for this system the HLB temperature is higher than $95 \pm 2{ }^{\circ} \mathrm{C}$ and which can exclude the possibility on its formation by PIT method (Figure 1).

It was observed a different behavior for the emulsions containing LEO, which presented initially an increase of conductivity with temperature and suddenly a rapid reduction in conductivity in a certain temperature value.

This suggests that the lavender oil addition influenced the HLB temperature. Moreover, it was observed that the higher the content of lavender essential oil in the formulation the lower was the HLB temperature (Figure 1).

According to Kanei et al. [20] there are several compounds presents in essential oils that present polar groups and amphiphilic properties and can influence the interface properties and also the HLB temperature. It is well-known that the HLB temperature of polyoxyethylene typesurfactant is highly influenced by the type of oil added. In the case of saturated hydrocarbons, the HBL temperature decreases with decreasing molecular weight of oil. The HLB temperature is low in the case of unsaturated aromatic hydrocarbons [20].

The same authors [20] when studied hydrocarbon oils having the same carbon number but different degrees of insaturation, i.e, when double bound was present in the molecule, observe that the HLB temperature of the system was lower. Moreover, it has been reported that the effect of an aldehyde or ketone in HLB temperature was not relevant comparing with the molecules with an end hydroxyl group [21].

Considering that the main component present in Lavandula officinalis oil are linalool and linalyl acetate, so alcohol and ester functions and also double bound, the presence of this compound could decrease the HLB temperature.

Between the formulations studied, that having PFO:LEO (5.0:5.0) was the only one that could be formed by PIT, considering that the temperature used in the emulsification method was $75 \pm 2^{\circ} \mathrm{C}$ and its HLB temperature was observed at $70 \pm 2{ }^{\circ} \mathrm{C}$.

It can be suggested that it is possible to obtain the emulsion PFO:LEO (5.0:5.0) by the HLB temperature method and the formation of nanoemulsion was mainly caused by the changing in the volume fraction (EPI method). Previous studies suggests that the main requirement for the formation of bluish $\mathrm{O} / \mathrm{W}$ nanoemulsions is to achieve a complete solubilization of oil phase in the bicontinuous phase formed in at the phase inversion point [10].

In addition, when used heating, there is a decrease of oil viscosity and hence decrease of the cohesion forces between oil molecules, promoting a better solubilization of oil in the bicontinuous phase and leading to smaller droplets $[9,22]$.

Emulsions that presented most desired characteristics had not LEO only, but also a lower content of oily phase (higher proportion of surfactant) suggesting that these factors were relevant to obtain emulsions with tiny droplets size. Morales et al. [23] reported similar results, because it was observed the increase of the granulometric distribution when the concentration of aqueous and oily phase was increased in a fixed proportion of surfactant.

Furthermore, the interfacial area in nanoemulsions is significantly higher when compared to the interfacial area of macroemulsions with 


\begin{tabular}{|c|c|}
\hline PFO:LEO $(\% \mathbf{w} / \mathbf{w})$ & Diameter size $(\mathbf{n m})$ \\
\hline $6: 0$ & $268 \pm 3.0$ \\
\hline $7.0: 0.0$ & $283 \pm 3.0$ \\
\hline $5.0: 1.0$ & $38 \pm 4.0$ \\
\hline $7.0: 1.0$ & $206 \pm 15.0$ \\
\hline $8.0: 1.0$ & $291 \pm 4.0$ \\
\hline $5.0: 2.0$ & $54 \pm 3.0$ \\
\hline $8.0: 2.0$ & $204 \pm 5.0$ \\
\hline $5.0: 5.0$ & $105 \pm 10.0$ \\
\hline $7.0: 5.0$ & $210 \pm 13.0$ \\
\hline $10.0: 5.0$ & $288 \pm 30.0$ \\
\hline
\end{tabular}

Table 12: Nanoemulsion diameter size $(\mathrm{nm})$ after centrifugation cycles and thermic stress.
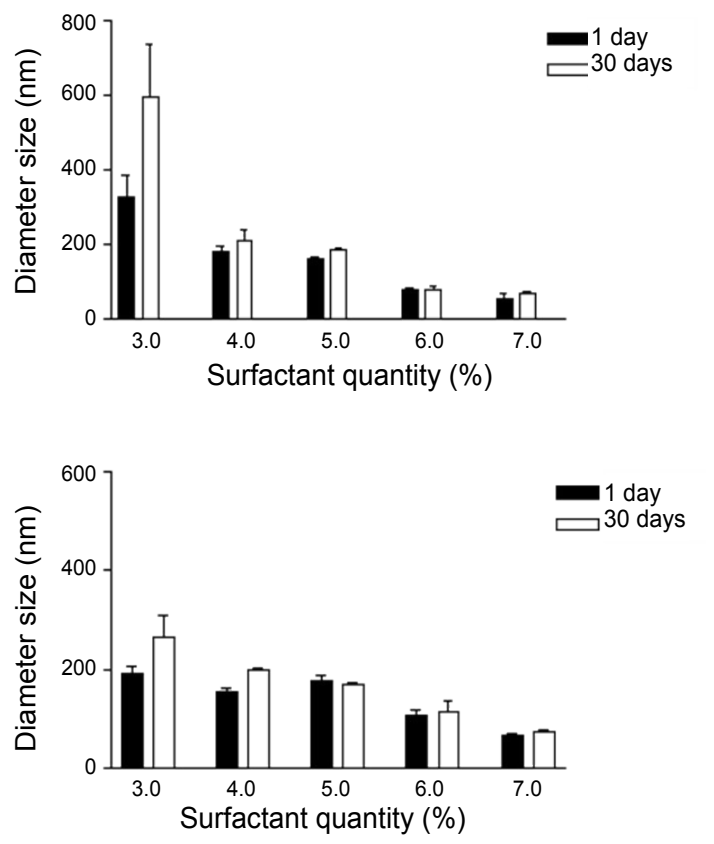

$(5: 5)$

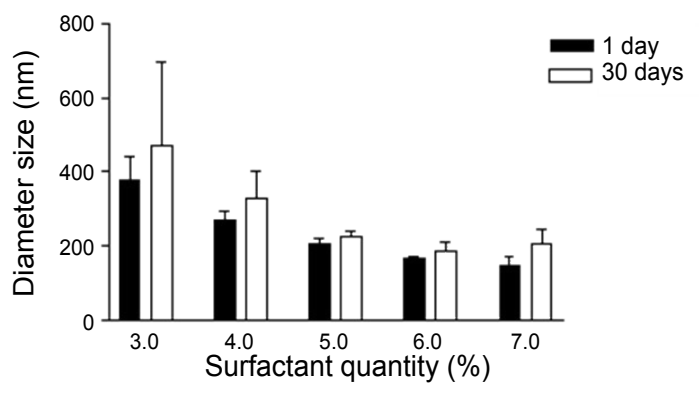

Figure 2: PFO:LEO $(5: 1,5: 2,5: 5)$ nanoemulsions with different amounts of surfactant within 24 hours of preparation (1day) and 30 days.

the same aqueous phase/surfactants proportion. It is explained by the fact that the oily phase is dispersed into smaller globules, making with that the total interfacial area of the dispersed phase is larger and therefore requires a minimum amount of surfactant capable of forming a proper interfacial film.

\section{Granulometric distribution measurement}

It was observed that nanoemulsions obtained with addition of lavender essential oil presented a decrease in size distribution than those in which the oily phase was composed just by PFO.

The behavior of essential oil components was investigated indicating that it can penetrate in the interlayer acting as a co-surfactant [20].

In our nanosystem, lavender essential oil not only decreased the droplet size but also provided a better stability of the system. It is well accepted that, for dispersed systems, the smaller the droplet size the higher the stability.

The emulsions PFO:LEO (5.01.0), PFO:LEO (5.0: 2.0) and PFO:LEO (5.0:5.0) showed smaller droplets size $(38 \pm 4,54 \pm 3$ and $105 \pm 10$, respectively) and it was studied the stability of these emulsions during 60 days in relation to the particle size (Table 12).

The droplet size is an important data in the stability analysis, so faster the droplet size increases, faster will occur the instability process as creaming or phase separation [24].

There was no significant variation in the particle size of the system in the temperature of $25 \pm 2^{\circ} \mathrm{C}$ and in the temperature of $4 \pm 2^{\circ} \mathrm{C}$ during the period of the study. At $45 \pm 2^{\circ} \mathrm{C}$, there was a change in the size of the droplets as well as in the polydispersity index, which is expected since the temperature increases the kinetic energy of the system, increasing the possibility to occur instability phenomena. Besides, the oily phase composed by volatile oil may have caused rupture of the interface by evaporation of its molecules.

It was observed a decrease in the particle size distribution by increasing the amount of surfactant for all formulations (Figure 2). For $3.0 \%$ and $4.0 \%$ of surfactants the granulometic profils were polydisperse and the globules of nano emulsions has a diameter size greater than the others. These results are in agreement with reported by Fernandez et al. [10] suggest that there is a minimum surfactant concentration to form stable nanoemulsions and the higher the polydispersity index , processes will occur more rapidly instability caused as the increase in the diameter size of globules. The increase in the diameter size after 30 days was significant in PFO:LEO (5.0:1.0) with 3.0\% surfactant (t-test , $\mathrm{p}=0.0142)$ and PFO:LEO (5.0:2.0) with $4.0 \%$ surfactant (t-test, $\mathrm{p}=0.003$ ). For PFO:LEO (5.0:5.0) nanoemulsions the formulation containing $7.0 \%$ surfactant also showed a significant increase in globule size ( $t$ test ,$p=0.0384$ ) in the same time. In systems with excess surfactants, there is increased formation of micelles, which can facilitate the mass transport of oil molecules from smaller to larger globules, which may result in an increase in particle size as a function of time.

The zeta potential is a tool for estimating the stability of emulsions because it determines the electrostatic repulsion between the globules [25-27]. Electrostatic stabilization is very sensitive to ionic charge near the interface of the solid solution. Thus, when the electrolyte concentration increases, the ionic double layer is compressed due to the ionic attraction forces, resulting in reduction of its thickness and the extent of reducing electrostatic repulsion force. A reduction in the electrical potential of the double layer causes a reduction in total electric potential, compromising the stability of the emulsion. The $\mathrm{pH}$ value is related to the dissociation of the ions and hence the interaction of these with the region of the interface eletronically loaded globules. The mean zeta potential values obtained after $24 \mathrm{~h}$ of manipulation to PFO:LEO (5.0:1.0), PFO:LEO (5.0:2.0) and PFO:LEO (5.0:5.0) |-37.6 \pm $1.022||-38.33 \pm 0.85 \mid$, and $|-27.76 \pm 1.105|$, respectively (Figure 3 ). The value of zeta potential determined for PFO:LEO (5.0:5.0) reinforces the theory that electric charge can greatly influence the stability of $\mathrm{O} / \mathrm{W}$ emulsions formulated with nonionic surfactants and the electrostatic 


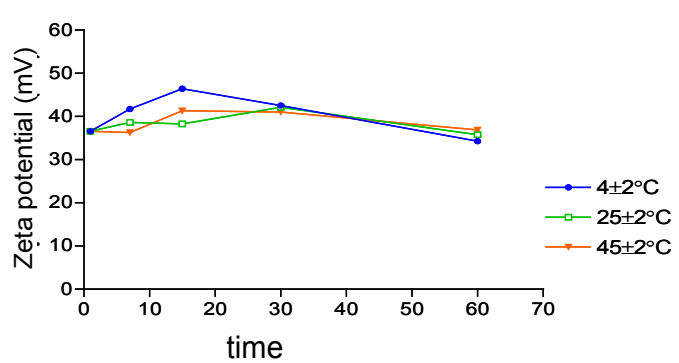

$(5: 2)$
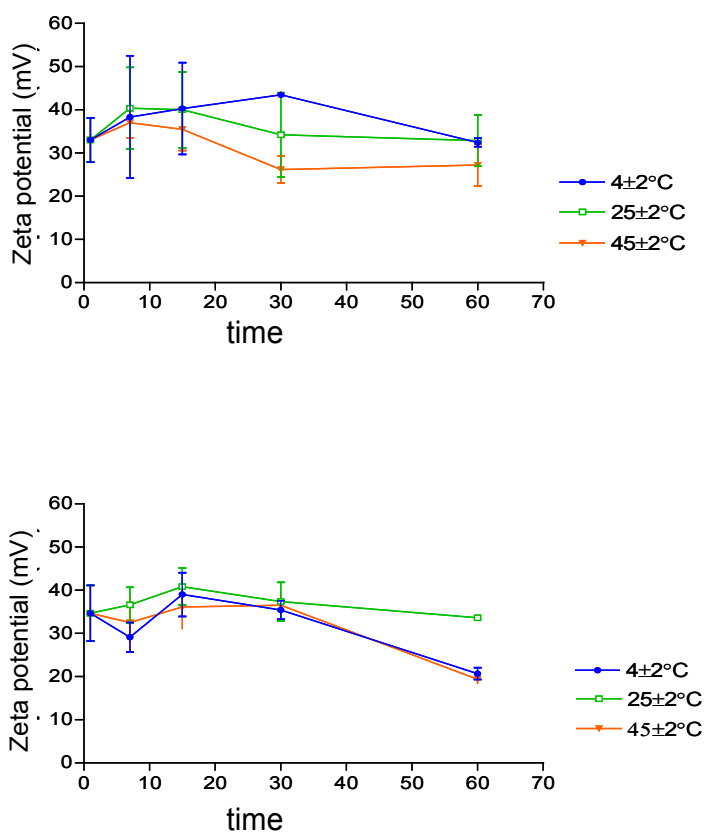

Figure 3: PFO:LEO $(5: 1,5: 2,5: 5)$ nanoemulsions zeta potential (in module) stored at room temperature $25 \pm 2^{\circ} \mathrm{C}, 4 \pm 2^{\circ} \mathrm{C}$ and $45 \pm 2^{\circ} \mathrm{C}$ within 60 days.

stability not being the main mechanism involved in the stabilization mechanism for these systems.

The stirring rate was shown to be a critical parameter for this system, and the speed was $600 \mathrm{rpm}$ which gave dispersions with the formation of the smaller sizes of globules (Figure 4). The emulsification process is complex and involves many phenomena that occur simultaneously as forming the dispersed phase, surfactants and adsorption of the collision of the globules formed, which can or not cause the coalescence. Each of these events occurs numerous times during emulsification, which shows that this process is dynamic [8]. At initial stirring time we observe the formation of disperse phase, but as stirring is continued, it happen an increase in particles collision increasing the possibility of coalescence [11]. The reasons for the phenomenon of stabilization of the globules is dependent on the stirring speed and time and can be attributed to the distribution of the emulsifier between the phases; the slow formation of the interfacial film or the interruption of film formation by continuous stirring [28]. In the case of nanoemulsions stirring speed is a more critical parameter because of the high fluidity of the natural system that does not require the collision barriers, different from conventional emulsions which typically have a higher viscosity.
Solé et al. [29] noted that the high-energy emulsification using Ultra Turrax and ultrasound produces emulsions with size greater than those prepared by the method of EPI in a system composed of potassium oleate- oleic acid- C12E10 / hexadecane. In this experiment it was found that the nanoemulsions with smaller globules were formed by high speed agitation since the aqueous phase was added slowly. This can be interpreted due to the fact that high speed agitation to facilitate complete solubilization of oil during emulsification process $[9,30]$.

After 30 days we can observe (Figure 5) the increase in diameter globules with the addition of PEG derivatives, but the nano emulsions maintained the diameter size lesser than $200 \mathrm{~nm}$.

According O'Lenick et al. [31] Silicon differ organic compounds by possessing very weak intermolecular attractive forces. It consists of chains $\mathrm{Si}$ - O- $\mathrm{Si}$ that is organized structurally occupying more space than $\mathrm{C}-\mathrm{O}-\mathrm{C}$ or $\mathrm{C}-\mathrm{C}$ chains. Although many silicones having polar or nonpolar groups in their chains become more hydro or liposoluble its basic structure is not soluble in water and in many nonpolar solvents, thus forming a third phase [31]. These characteristics of silicones may have difficult the emulsification process.

Formulations added carbinol $5562^{\circ}$ and $245^{\circ}$ Fluid showed signs of instability unlike that formulated with silicone to $190^{\circ}$ Fluid. This

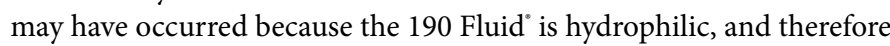
soluble in the aqueous phase while carbinol $5562^{\circ}$ and $245^{\circ}$ Fluid are lipophilic. Possibly the amount of surfactant used was not sufficient to emulsify the oil phase, or their steric structure (long chain molecule) may have interfered with the formation of the interfacial film, changing the intermolecular interactions of surfactants chains with the oil phase .

In the thermal stress, at $75^{\circ} \mathrm{C}$ PFO:LEO (5.0:5.0) nanoemulsion containing the silicone 245 Fluid $^{\circ}$ showed phase separation (Table 13). Possibly the volatility of this silicon derivative can cause the rupture of the interfacial layer leading to phase separation. The diameter size for nanoemulsions showing adequate intrinsic stability was determined in 24 and after 30 days at room temperature $\left(25 \pm 2^{\circ} \mathrm{C}\right)$ (Figure 6).

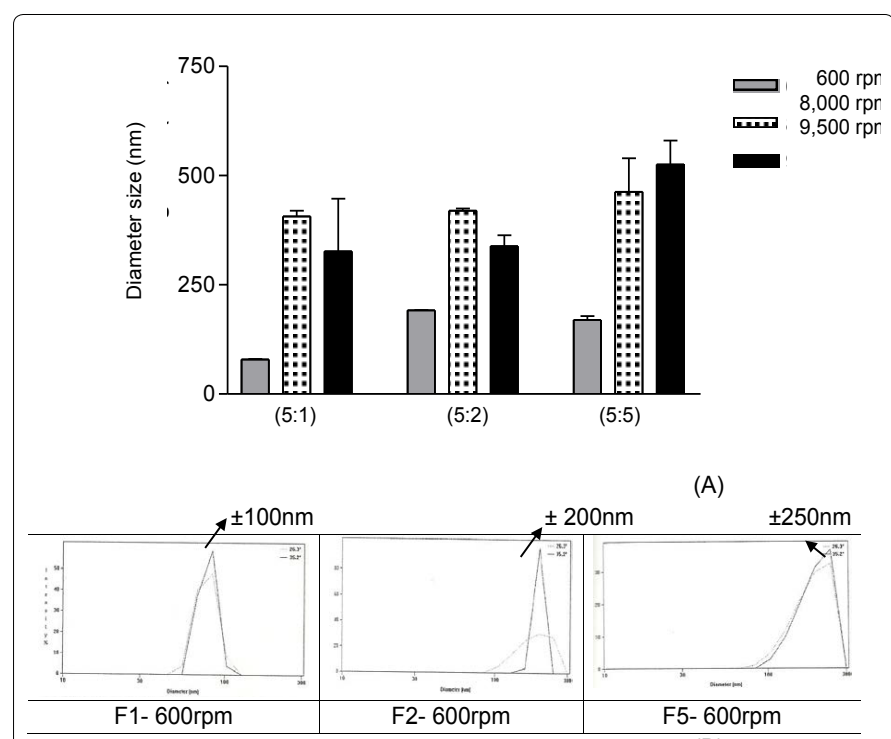

(B)

Figure 4: PFO:LEO $(5: 1,5: 2,5: 5)$ nanoemulsions particle size distribution subjected to $600,8,000$ and $9,000 \mathrm{rpm}$ for 5 minutes (A) and gralunometric profil for PFO:LEO $(5: 1,5: 2,5: 5)$ prepared at 600 rpm for 5 minutes 
5:1)

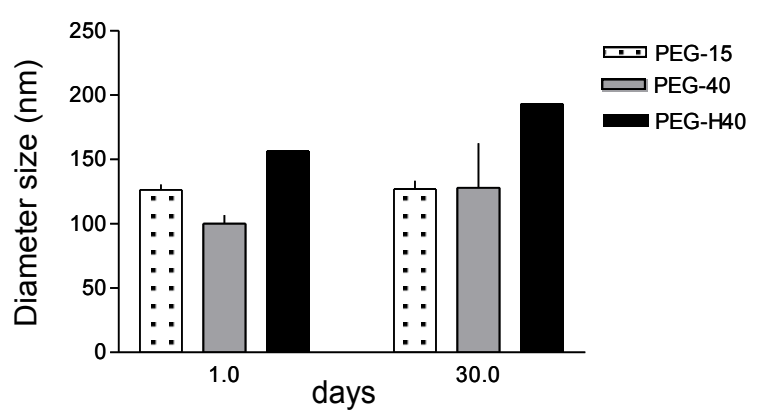

j:2)

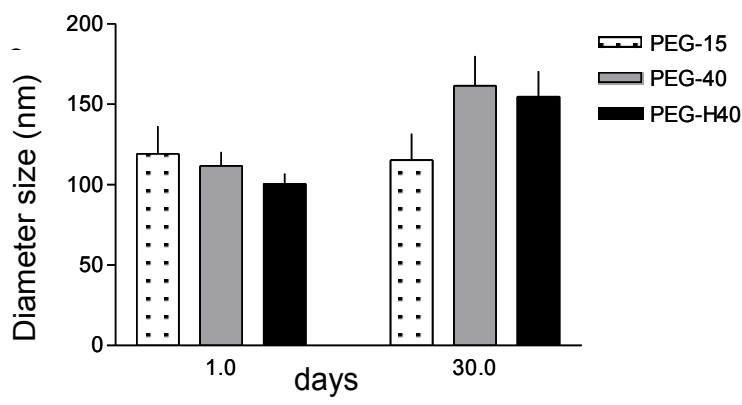

$5: 5)$

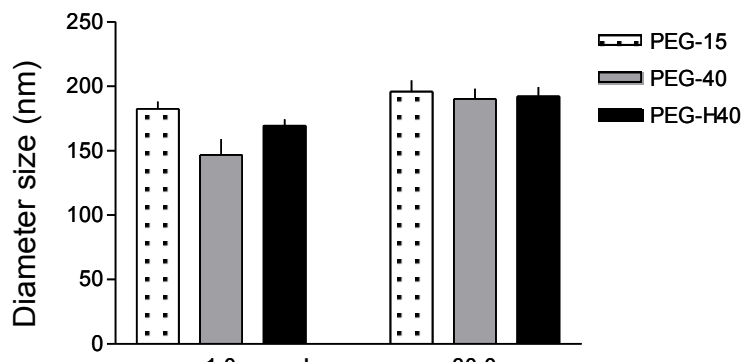

Figure 5: PFO:LEO nanoemulsions diameter size $(\mathrm{nm})$ with different cosurfactants quantity at different time.

\section{Evaluation of the constituents of lavender oil by GC / MS [13]}

The lavender oil was extracted from the nanoemulsions subjected to stability tests by Clevenger. The period of 3 hours was standardized for extraction. After recovery of the essential oil was performed the quantification of major compounds by GC / MS. Figure 7 show a partial chromatogram performed to lavender essential oil ( $1^{\text {st }}$ day and after $60^{\text {th }}$ days at $25 \pm 2^{\circ} \mathrm{C}, 4 \pm 2^{\circ} \mathrm{C}$ and $45 \pm 2^{\circ} \mathrm{C}$ ). Table 14 shows the components found in lavender oil and after extracted from nanoemulsions submitted to temperatures of $4 \pm 2^{\circ} \mathrm{C}, 25 \pm 2^{\circ} \mathrm{C}$ and $45 \pm 2^{\circ} \mathrm{C}$ for 60 days. Table 15 shows the Kovat's index (IK) obtained from this study, IK found in the literature [13] and the index of similarity between the mass spectra when compared to data obtained from Wiley 7 . Linalyl acetate showed a significant reduction in percent after being subjected to accelerated stability test. At $45 \pm 2^{\circ} \mathrm{C}$ this reduction was $88.93 \%$, which indicates that this compound can be volatilized have undergone chemical reaction with other compounds in the formulation. Linalyl acetate is an ester, which is susceptible to hydrolysis when in medium of high water quantity. The compounds linalool, $\alpha$-terpineol and geranyl isobutyrate were present in greater quantity after the stability test, and the $a$-terpineol and geranyl isobutyrate increase their concentration particularly when stored at $45 \pm 2^{\circ} \mathrm{C}$. It is possible that these compounds are by-products of the chemical reactions involved in linalyl acetate .The possible hydrolysis of this compound can relate to the reduction of $\mathrm{pH}$ values observed in the formulations submitted to stability tests (Table 16).

\begin{tabular}{|c|c|c|c|c|c|c|c|c|c|c|}
\hline \multirow{2}{*}{$\begin{array}{c}\text { PFO:LEO } \\
(\% \mathrm{w} / \mathrm{w})\end{array}$} & \multirow{2}{*}{$\begin{array}{c}\text { Centrifugation } \\
\text { cycles }\end{array}$} & \multicolumn{9}{|c|}{ Thermic stress $\left( \pm 1^{\circ} \mathrm{C}\right)$} \\
\hline & & 40 & 45 & 50 & 55 & 60 & 65 & 70 & 75 & 80 \\
\hline 5.0:1.0- carb. & LC & $\mathbf{N}$ & $\mathbf{N}$ & $\mathbf{N}$ & $\mathbf{N}$ & $\mathbf{N}$ & $\mathbf{N}$ & $\mathbf{N}$ & $\mathbf{N}$ & OS \\
\hline $5.0: 1.0-245$ & $\mathbf{N}$ & $\mathbf{N}$ & $\mathbf{N}$ & $\mathbf{N}$ & $\mathbf{N}$ & $\mathbf{N}$ & $\mathbf{N}$ & $\mathbf{N}$ & $\mathbf{N}$ & OS \\
\hline $5.0: 1.0-190$ & $\mathbf{N}$ & $\mathbf{N}$ & $\mathbf{N}$ & $\mathbf{N}$ & $\mathbf{N}$ & $\mathbf{N}$ & $\mathbf{N}$ & $\mathbf{N}$ & $\mathbf{N}$ & $\mathbf{N}$ \\
\hline 5.0:2.0- carb. & LC & $\mathbf{N}$ & $\mathbf{N}$ & $\mathbf{N}$ & $\mathbf{N}$ & $\mathbf{N}$ & $\mathbf{N}$ & $\mathbf{N}$ & IC & os \\
\hline $5.0: 2.0-245$ & $\mathbf{N}$ & $\mathbf{N}$ & $\mathbf{N}$ & $\mathbf{N}$ & $\mathbf{N}$ & $\mathbf{N}$ & $\mathbf{N}$ & $\mathbf{N}$ & $\mathbf{N}$ & OS \\
\hline $5.0: 2.0-190$ & $\mathbf{N}$ & $\mathbf{N}$ & $\mathbf{N}$ & $\mathbf{N}$ & $\mathbf{N}$ & $\mathbf{N}$ & $\mathbf{N}$ & $\mathbf{N}$ & $\mathbf{N}$ & IC \\
\hline 5.0: 5.0 -carb. & LC & $\mathbf{N}$ & $\mathbf{N}$ & $\mathbf{N}$ & $\mathbf{N}$ & $\mathbf{N}$ & $\mathbf{N}$ & $\mathbf{N}$ & PS & OS \\
\hline $5.0: 5.0-245$ & LC & $\mathbf{N}$ & $\mathbf{N}$ & $\mathbf{N}$ & $\mathbf{N}$ & $\mathbf{N}$ & $\mathbf{N}$ & $\mathbf{N}$ & PS & OS \\
\hline 5.0: $5.0-190$ & $\mathbf{N}$ & $\mathbf{N}$ & $\mathbf{N}$ & $\mathbf{N}$ & $\mathbf{N}$ & $\mathbf{N}$ & $\mathbf{N}$ & $\mathbf{N}$ & $\mathbf{N}$ & OS \\
\hline
\end{tabular}

Carb. $=$ carbinol $^{\circledR} 5562 ; 245=245$ Fluid $^{\circledR} ; 190=190$ Fluid $^{\circledR} ; \mathrm{N}=$ normal; IC-= intense cremeation; $L C=$ light cremeation; $P S=$ phase separation

Table 13: Macroscopic analysis of PFO:LEO nanoemulsions added of silicones derivatives after centrifugation and thermic stress.

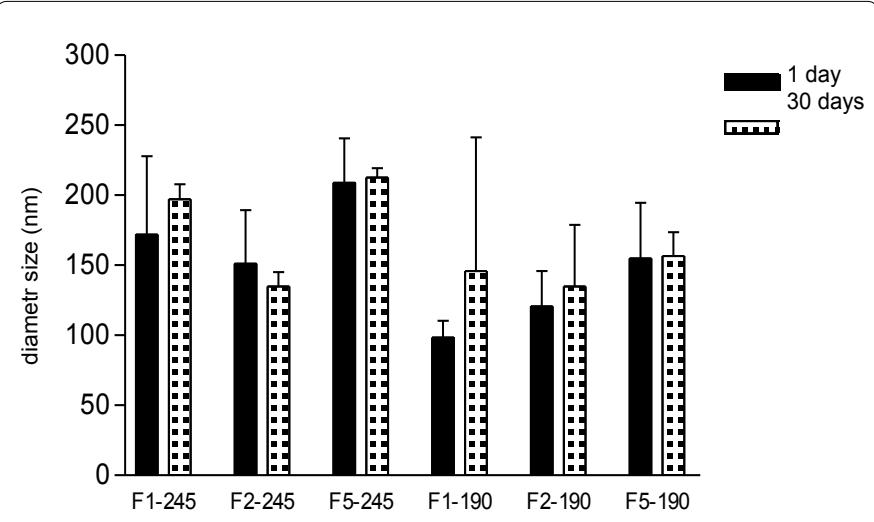

Figure 6: PFO:LEO $(5: 1,5: 2,5: 5)$ nanoemulsions particle size distribution added silicones 245 Fluid $^{\circledR}$ and 190 Fluid $^{\circledR}$.

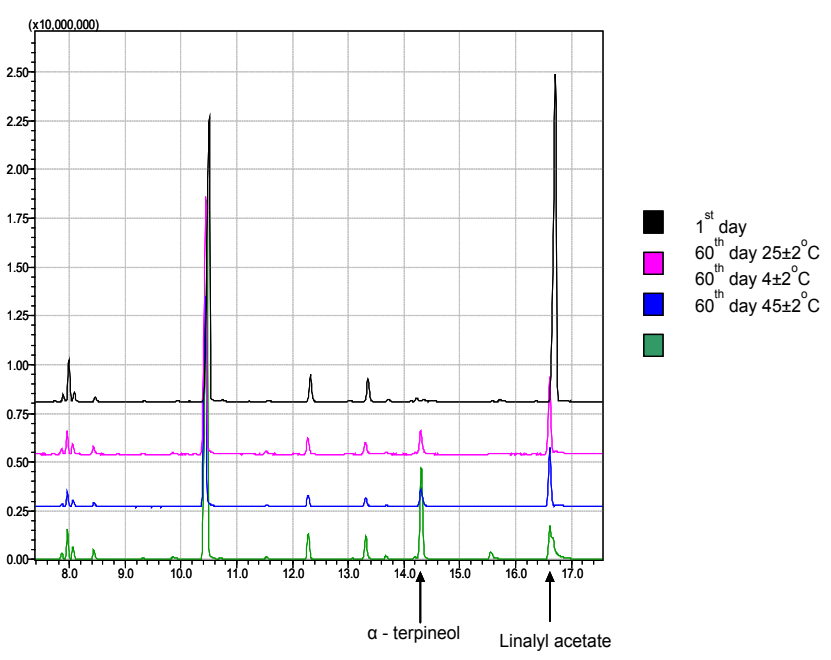

Figure 7: Partial chromatogram performed to lavender essential oil ( $1^{\text {st }}$ day and after $60^{\text {th }}$ days at $25 \pm 2^{\circ} \mathrm{C}, 4 \pm 2^{\circ} \mathrm{C}$ and $45 \pm 2^{\circ} \mathrm{C}$ ). 


\begin{tabular}{|c|c|c|c|c|c|c|c|c|c|}
\hline \multirow{2}{*}{$\begin{array}{c}\text { Storage conditions } \\
\text { Temperature }\left( \pm 2{ }^{\circ} \mathrm{C}\right) / \\
\text { Time (days) }\end{array}$} & \multicolumn{9}{|c|}{ Components (\%) } \\
\hline & 1,8- cineol & $\beta$-ocimene & linalol & camphor & borneol & Linalil acetate & $\beta$ - cariophylen & $\alpha$ - terpineol & geraniol \\
\hline One day & 3.69 & 1.33 & 37.40 & 3.05 & 2.60 & 45.14 & 1.44 & 0.30 & 0.10 \\
\hline $25 / 60$ & 3.20 & 2.78 & 54.54 & 3.14 & 2.66 & 16.10 & 1.64 & 5.65 & 1.56 \\
\hline $4 / 60$ & 3.67 & 3.11 & 53.50 & 3.24 & 2.55 & 16.10 & 1.53 & 5.62 & 2.21 \\
\hline $45 / 60$ & 2.93 & 2.35 & 50.98 & 3.23 & 2.93 & 5.00 & 1.71 & 12.44 & 3.21 \\
\hline
\end{tabular}

Table 14: Components found in lavender oil and after extracted from nanoemulsions submitted to temperatures of $4 \pm 2^{\circ} \mathrm{C}, 25 \pm 2^{\circ} \mathrm{C}$ and $45 \pm 2^{\circ} \mathrm{C}$ for 60 days.

\begin{tabular}{|c|c|c|c|c|c|c|c|c|c|}
\hline Organic compounds & 1,8- cineol & $\beta$-ocimene & Linalool & camphor & borneol & Linalil acetate & $\beta$ - cariophylen & $\alpha$ - terpineol & geraniol \\
\hline$K$ Index founded & 1030 & 1043 & 1101 & 1145 & 1170 & 1249 & 1414 & 1193 & 1248 \\
\hline $\mathrm{K}$ index cited in literature & 1033 & 1040 & 1098 & 1143 & 1165 & - & 1418 & 1189 & 1250 \\
\hline Similarity index & 97 & 97 & 98 & 97 & 98 & & 95 & 95 & 98 \\
\hline
\end{tabular}

Table 15: Kovat 's index (IK) obtained from this study, IK found in the literature [13] and the index of similarity between the mass spectra found and in the literature.

$\downarrow$ Formulation (PFO:LEO)

\begin{tabular}{|c|c|c|c|c|c|c|}
\hline$\downarrow$ Formulation (PFO:LEO) & \multicolumn{6}{|c|}{ pH value } \\
\hline \multicolumn{2}{|c|}{$\left(25 \pm 2^{\circ} \mathrm{C}\right)$} & \multicolumn{4}{|c|}{$\left(45 \pm 2^{\circ} \mathrm{C}\right)$} & \\
\hline Time (day) $\rightarrow$ & 1 & 7 & 30 & 1 & 7 & 30 \\
\hline$(5: 1)$ & $5.97 \pm 0.05$ & $5.98 \pm 0.05$ & $5.95 \pm 0.05$ & $5.97 \pm 0.005$ & $5.92 \pm 0.005$ & $5.77 \pm 0.02$ \\
\hline$(5: 2)$ & $5.97 \pm 0.0058$ & $5.97 \pm 0.0058$ & $5.96 \pm 0$ & $5.97 \pm 0.0058$ & $5.90 \pm 0.0058$ & $5,80 \pm 0,010$ \\
\hline$(5: 5)$ & $5.96 \pm 0$ & $5.96 \pm 0.0058$ & $5.96 \pm 0.0058$ & $5.96 \pm 0$ & $5.84 \pm 0.021$ & - \\
\hline
\end{tabular}

(-) not performed

Table 16: PFO:LEO $(5: 1,5: 2,5: 5)$ nanoemulsions $\mathrm{pH}$ values subjected to different temperatures for 1,7 and 30 days.

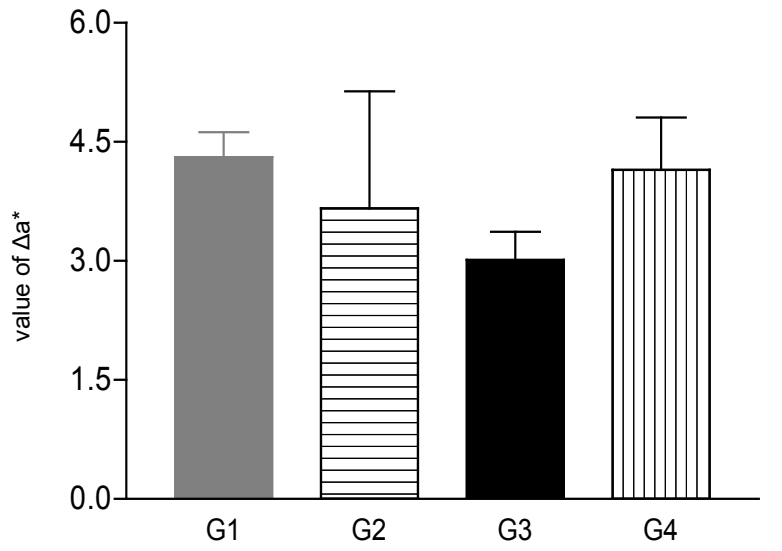

Figure 8: $\Delta \mathrm{a}^{*}$ values obtained from animals of group $1(\mathrm{G} 1)$, Group 2 (G2), group 3 (G3), Group 4 (G4).

In vivo study- evaluation of anti-inflammatory activity of emulsions

The assessment of erythema through the apparatus Minolta Chroma Meter" had already been measured as the method of analysis of inflammatory parameters in previous studies $[16,32,33]$. The evolution of erythema was evaluated in each animal groups: group 1 - negative control, group 2 - received treatment based emulsion without active, group 3 - received treatment with the emulsion containing 5.0\% of the essential oil of lavender; Group 4 - received treatment with the pure essential oil. The difference in the values of $\left(\Delta \mathrm{a}^{*}\right)$ expressing redness of the skin is presented in Figure 8 and values of $\left(\Delta \mathrm{a}^{*}\right)$ found before irradiation and after 2, 5, 10, 24, 48 and 72 hours (Figure 9):

It is remarkable that of group 3 showed less erythema than animals from the other groups. The difference in the amount of $\left(\Delta \mathrm{a}^{*}\right)$ to the groups was considered significant by being indicative that the anti- inflammatory properties of lavender oil deserve to be studied for more complex methods which investigate other signs of inflammation $\mathrm{t}(\mathrm{p}=0.0092)$ test. But the group 4 animals treated with pure lavender essential oil showed redness similar to the control group and severe skin desquamation and dehydration in 48 and 72 hours. The lavender oil is rich in mono terpenes, famously used as absorption promoters. Absorption promoters are substances capable of increasing the absorption of molecules across the stratum corneum. Terpenes are considered safe by the Food and Drug Administration (FDA) and in most cases do not cause toxicity $[34,35]$. In the case of animals treated with this oil, it is possible that the amount of these components was sufficient to cause an increase in local circulation and consequent increase in skin redness. Moreover, the constant application may have caused a disruption of the stratum corneum that may have led to a transepidermal water loss leading to skin dehydration and desquamation. According Marquele- Oliveira (2007) [33], the flaking may be due to a possible healing effect of the oil, the greater proliferation of epidermal cells to heal the injury. The results suggest that in addition to investigating the anti-inflammatory effect by the proposed method, more complex studies should be conducted to elucidate the effect of the essential oil of lavender on other inflammatory parameters in order to clarify the possible anti-inflammatory mechanisms of this oil, as well as evaluating the dosage suitable for that does not cause skin irritation or dehydration.

\section{Conclusion}

The addition of lavender essential oil did not cause changes in the HLB value required by the system;

It was possible to obtain stable nanoemulsions containing PFO, LEO from hydrophilic surfactants PEG -30 castor oil and PEG -40 castor oil associated with the lipophilic sorbitan monooleate; Minimum surfactant concentration necessary for the formation of nanoemulsions was $5.0 \%$. The addition of LEO in the system consisting of PFO, PEG -30 castor oil, -sorbitan monooleate and water caused reduction in size compared to nanoemulsions without this oil emulsion containing the 


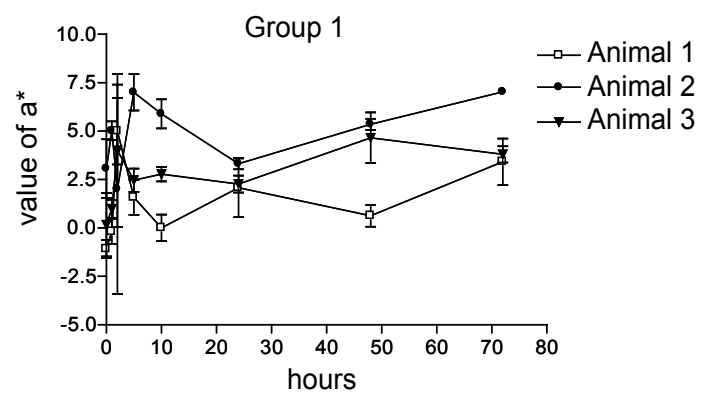

Group 3

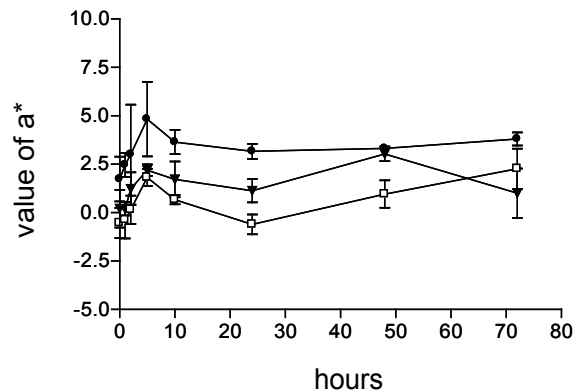

$\rightarrow-$ Animal 1

- Animal 2

- Animal 3
Group 4

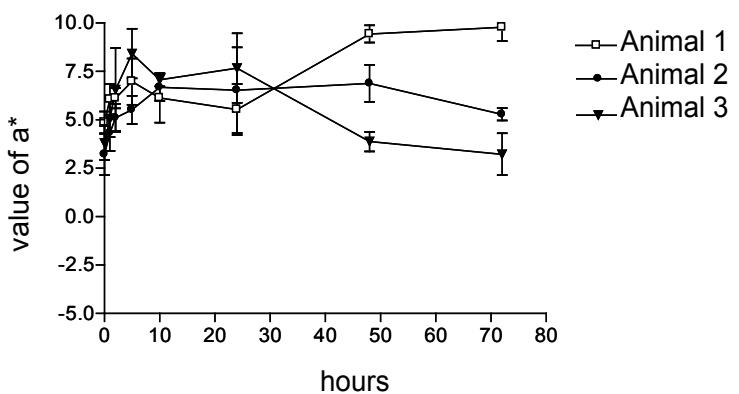

Figure 9: Values of $\Delta \mathrm{a}^{*}$ shown by the animals of groups 1, 2, 3 and 4 before irradiation and 2, 5, 10, 24, 48, 72 hours after the irradiation.

same ratio of the oily phase / surfactant/water; It could not determine the PIT emulsions consisting of PFO and the mixture of surfactants PEG - 30 castor oil and sorbitan monooleate, indicating that nanoemulsion formation was not related to temperature; We can get the PFO:LEO (5.0:5.0) nanoemulsion by both methods of low energy emulsification (PIT and EPI), but in PFO:LEO (5.0:1.0) and PFO:LEO (5.0:2.0) the process involved is the EPI; The stirring rate was a critical parameter to obtain nanoemulsions by the EPI method, with the speed of $600 \mathrm{rpm}$ was the most effective;

The addition of electrolytes destabilized the PFO:LEO (5.0:5.0) nanoemulsion when subjected to high temperature values; The chromatographic analysis of nanoemulsions containing LEO and under different conditions of time and temperature indicate no change to the LEO; The addition of silicone caused instability processes such as creaming or significant change in the diameter size nanoemulsions as function of time; The emulsion containing LEO oil caused reduction of erytheme being worthy of further study for a more complete assessment of its probable anti-inflammatory activity.

\section{References}

1. Hudson R (1996) The value of lavander for rest and activity in the elderly patient. Complement Ther Med 4: 52-57.

2. Appleton J (2014) Lavender Oil for Anxiety and Depression- Review of the literature on the safety and efficacy of lavender. Natural Medicine Journal 4.

3. Cavanagh HM, Wilkinson JM (2002) Biological activities of lavender essential oil. Phytother Res 16: 301-308.

4. Boelens MH, Arquette JD (1995) Chemical and sensory evaluation of Lavandula oils. Perfum Flav 20: 23-51.
5. Bruneton J (1993) Pharmacognosie. Phytochimie Plantes medicinales. (2ndedn), Paris: Tec Doc 915.

6. Camargo MFP (2008) Development of nanoemulsions passion fruit oil (Passiflora edulis) and essential oil of lavender (Lavandula officinalis) and evaluation of anti-inflammatory activity Ribeirão Preto. Thesis (Master) Faculty of Pharmaceutical Sciences of Ribeirão Preto, University of São Paulo.

7. Marszal L (1987) HBL of nonionic surfactants: PIT and EPI methods In: Schick MJ Surfactant Science Series, Nonionic Surfactants. Physical Chemistry, New York: Marcel Dekker Inc 23: 493-547.

8. Tadros T, Izquierdo P, Esquena J, Solans C (2004) Formation and stability of nano-emulsions. Adv Colloid Interface Sci 108-109: 303-18.

9. Izquierdo P, Feng J, Esquena J, Tadros TF, Dederen JC, et al. (2005) The influence of surfactant mixing ratio on nano-emulsion formation by the pit method. J Colloid Interface Sci 285: 388-394.

10. Fernandez P, André V, Rieger J, Kühnle A, (2004) Nano-emulsions formation by emulsions phase inversion. Colloids and Surfaces A: Physicochemical and Engineering Aspects 251: 53-58.

11. Agência Nacional de Vigilância Sanitária-Anvisa (2004) [Brazil builds up a network of scientists to investigate infection outbreaks in health services]. Rev Saude Publica 38: 750 .

12. Ferrari M (1998) Obtaining and applying multiple emulsions containing oils Andiroba and Copaiba. Ribeirão Preto. Thesis (Master) - Faculty of Pharmaceutical Sciences of Ribeirão Preto, University of São Paulo.

13. Adams RP (1995) Identification of essential oil components by Gas chromatography/ Mass spectroscopy. Carol Stream: Allured Publishing Corporation.

14. Rosa FS (2002) Influence of a cutaneous absorption and ester derivatives of 5 - aminolevulinic acid in photodynamic therapy of skin cancer. Thesis (Ph.D.), Ribeirão Preto. Faculty of Pharmaceutical Sciences of Ribeirão Preto, University of São Paulo.

15. Chardon A, Cretois I, Hourseau C (1991) Skin colour typology and suntanning pathways. Int J Cosmet Sci 13: 191-208. 
Citation: Rocha- Filho PA, Camargo MFP, Ferrari M, Maruno M (2014) Influence of Lavander Essential Oil Addition on Passion Fruit Oil Nanoemulsions: Stability and In vivo Study. J Nanomed Nanotechnol 5: 198. doi:10.4172/2157-7439.1000198

16. Proksch E, Nissen HP, Bremgartner M, Urquhart C (2005) Bathing in a magnesium-rich Dead Sea salt solution improves skin barrier function, enhances skin hydration, and reduces inflammation in atopic dry skin. Int $J$ Dermatol 44: 151-157.

17. Aulton ME (1995) Pharmaceutics: The science of dosage form design, New York: Churchill Livingstone, 290-292.

18. Salager JL, Forgiarini A, Márquez L, Peña A, Pizzino A, et al. (2004) Using emulsion inversion in industrial processes. Adv Colloid Interface Sci 108-109: 259-72.

19. Florence AT, Attwood D (2003) Physicochemical principles of pharmacy, São Paulo.

20. Kanei N, Tamura Y, Kunieda H (1999) Effect of Types of Perfume Compounds on the Hydrophile-Lipophile Balance Temperature. J Colloid Interface Sci 218 $13-22$.

21. Latreille B, Paquin $P$ (1990) Evaluation of emulsion stability by centrifugation with conductivity measurements. J Food Sci 55: 1666-1668.

22. Liu W, Sun D, Li C, Liu Q, Xu J (2006) Formation and stability of paraffin oilin-water nano-emulsions prepared by the emulsion inversion point method. J Colloid Interface Sci 303: 557-563.

23. Morales D, Guiérrez JM, Gracia-Celma MJ, Solans YC (2003) A study of the relation between bicontinuous microemulsions and oil/ water nano-emulsion formation. Langmuir 19: 7196-7200.

24. Jeong MW, Oh SG, Kim YC (2001) Effects of amine oxide compounds on the zeta potential of emulsion droplets stabilized by phosphatidylcholine. Colloids and Surfaces A: Physicochemical and Engineering Aspects 181: 247-256.

25. Friberg SE (1988) Theory of Emulsions. In: Lieberman HA, Rieger, MM, Banker GS, Pharmaceutical Dosage Forms: Disperse Systems, Marcel Dekker Inc, NY.
26. Kulmyrzaev AA, Schubert $\mathrm{H}$ (2004) Influence of $\mathrm{KCl}$ on the physicochemical properties of whey protein stabilized emulsions. Food Hydrocolloids 18: 13-19.

27. Zeta- meter Inc, Potencial Zeta: a complete course in 5 minutes, Staunton VA, USA.

28. Lachman L, Lierberman HA, Kanig JL (1986) The theory and Practice of Industrial Pharmacy. Philadelphia, Lea \& Febiger 100-122.

29. Solé I, Maestro A, Pey CM (2006) Nano- emulsions preparation by low energy methods in an ionic surfactant system. Colloids and Surfaces A: Physicochemical and Engineering Aspects 288: 138-143.

30. Forgiarini A, Esquena J, González C, Solans C (2001) Formation of nanoemulsions by low- energy emulsification methods at constant temperature. Langmuir 17: 2076-2083.

31. O'Lenick A (2000) Silicone emulsions and surfactants. J Surf Deterg 3: 387393.

32. Chan, SY, Po ALW (1992) Quantitative assessment of non-steroidal antiinflammatory topical products in nicotinate- induced erythema using tristimulus colour analysis. Int J Pharmaceutics 83: 73-86.

33. Marquele-Oliveira F (2007) Development of topical formulations containing fotoquimioprotetoras propolis extract: stability study, eretenção skin permeation in vitro and in vivo efficacy. Thesis (Ph.D. in Drugs and Cosmetics). Faculty of Pharmaceutical Sciences of Ribeirão Preto. University of São Paulo.

34. Okabe H, Obata Y, Takayama K, Nagai T (1990) Percutaneous absorption enhancing effect and skin irritation of monocyclic monoterpenes. Drug Des Deliv 6: 229-238.

35. Aqil M, Ahad A, Sultana Y, Ali A (2007) Status of terpenes as skin penetration enhancers. Drug Discov Today 12: 1061-1067. 